\title{
Economic and Efficiency Analysis of China Electricity Market Reform Using Computable General Equilibrium Model
}

\author{
Jieting Yin ${ }^{1}$, Qingyou Yan ${ }^{2, *}$, Kaijie Lei ${ }^{3}$, Tomas Baležentis ${ }^{4, *}$ and Dalia Streimikiene ${ }^{4}$ (i) \\ 1 School of Information, Beijing Wuzi University, Beijing 101149, China; yinjieting@bwu.edu.cn \\ 2 School of Economic and Management, North China Electric Power University, Beijing 102206, China \\ 3 DongGuan Power Supply Bureau, GuangDong Power Grid Corp., DongGuan 523008, China; \\ leikaijie518@163.com \\ 4 Lithuanian Institute of Agrarian Economics, Vilnius 01113, Lithuania; dalia@mail.lei.lt \\ * Correspondence: yanqingyou@ncepu.edu.cn (Q.Y.); tomas@laei.lt (T.B.); Tel.: +370-52-262-2085 (T.B.)
}

Received: 4 December 2018; Accepted: 3 January 2019; Published: 11 January 2019

\begin{abstract}
China's electricity industry has been undergoing a process of regulatory reform. This study aims to analyse the impact of liberalization on the electricity market assuming different degrees of scope of the reforms by applying a computable general equilibrium (CGE) model. In this paper, we consider the three sub-sectors of the electricity industry, namely generation, transmission and distribution. We assume that the reform will phase out the entry barriers on the generation side and allow for competition on the distribution side, while keeping the transmission side under regulation. The results showed that the reform could enhance efficiency in the electricity sector and reduce energy prices for households. Introduction of a complete competition model would decrease welfare by 5.394 billion yuan, if contrasted to a limited competition model. The composite energy price would decline under both scenarios, whereas the quantity of energy consumed by the households would go up. This research, thus, contributes to literature on the economic effects of China's electric power market reform, and can be used as a case study to support policy decisions for the decision-makers.
\end{abstract}

Keywords: electricity market reform; computable general equilibrium (CGE) model; liberalisation; regulation; China

\section{Introduction}

Being an important basic industry for national economic development, the electric power industry acts as a strong natural monopoly. This mode of operation lacks competitive pressure and may induce a lower level of the operation efficiency. In order to move away from the monopolistic electricity market structure towards a more competitive one, various countries have embarked on electricity market reforms introducing competitiveness there. The objectives of climate change mitigation have also played a role in shaping the energy policy [1-6]. China's electric power industry reform began in 1985 and has gone through the three stages: Fund collection for electricity, separating the functions of the government from those of enterprises, and introduction of competition in the power generation industry [7,8]. In March 2015, the State Council of People's Republic of China released Opinions Regarding the Deepening of the Power Sector's Reform (Document No. 9). The document put forward a power industry reform structure of "regulating the middle, opening both ends", which marks a new stage of the market-oriented reform of China's electric power industry.

Regulating the middle means that the profit of the power grid no longer depends on the difference purchase and sale price of the electricity but rather to charge for transmission and distribution. The price of transmission and distribution is approved by the government so that it covers grid operation 
costs and generates a reasonable profit margin. Therefore, the pricing system introduced during the reform ensures the profit of power grid enterprises. However, state control is required to eliminate unreasonable costs. Opening both ends means that power generation enterprises and power retailing enterprises are allowed to enter the market and facilitate direct transactions with power consumers. Through competition, the enterprises determine the quantity and price of electricity.

Given the trend of economic growth in China, the annual rate of growth in electricity consumption was 3.61\% in 2013-2016, while the annual growth of the installed capacity (the total amount of power available from generating units) was $9.69 \%$, i.e., the growth in generation capacity (the amount of the power produced by generating units) was much faster than the growth of social demand for electricity (see Figure 1). At the same time, the utilisation hours of thermal power units have been reduced from $5012 \mathrm{~h}$ to $4165 \mathrm{~h}$. Under the effect of a market price competition mechanism, the direct transaction price between power generation enterprises and power users naturally tends to decline.

China's electricity retail industry has developed rapidly since the promulgation of Document No. 9 of the electric power reform (see Figure 2). As of March 2017, more than 6000 electric power sales companies have been established nationwide. This has affected previously monopolistic power transmission, distribution and retail sectors. According to the 13th Five-Year Plan for Electric Power Development, the establishment of power trading institutions was completed by the end of 2016 and the cultivation of market competition subjects on the selling side will be completed by the end of 2018 . In the retail electricity market, $35 \mathrm{~kW}$ and above users are free to choose their retailer in 1 to 3 years after 2018, $10 \mathrm{~kW}$ and above users will be able to do so in the next 5-10 years. This suggests the scale of the electricity trade in the competitive market will continue to expand in China. The schedule of electricity market liberalization in China is shown in Table 1.

The electricity market liberalization in China is likely to pose multifaceted consequences for both power producers and consumers. Therefore, it is important to identify the major effects and their implications. In this paper, we assess the potential impacts of electric power market reform in China by employing the CGE model. The novelty of this paper is that we consider subsectors of the electricity sector (generation, transmission, distribution and retail) rather than the electricity sector as a whole. This kind of analysis allows one to obtain more detailed insights into the effects of the electricity market liberalization in China for different agents.

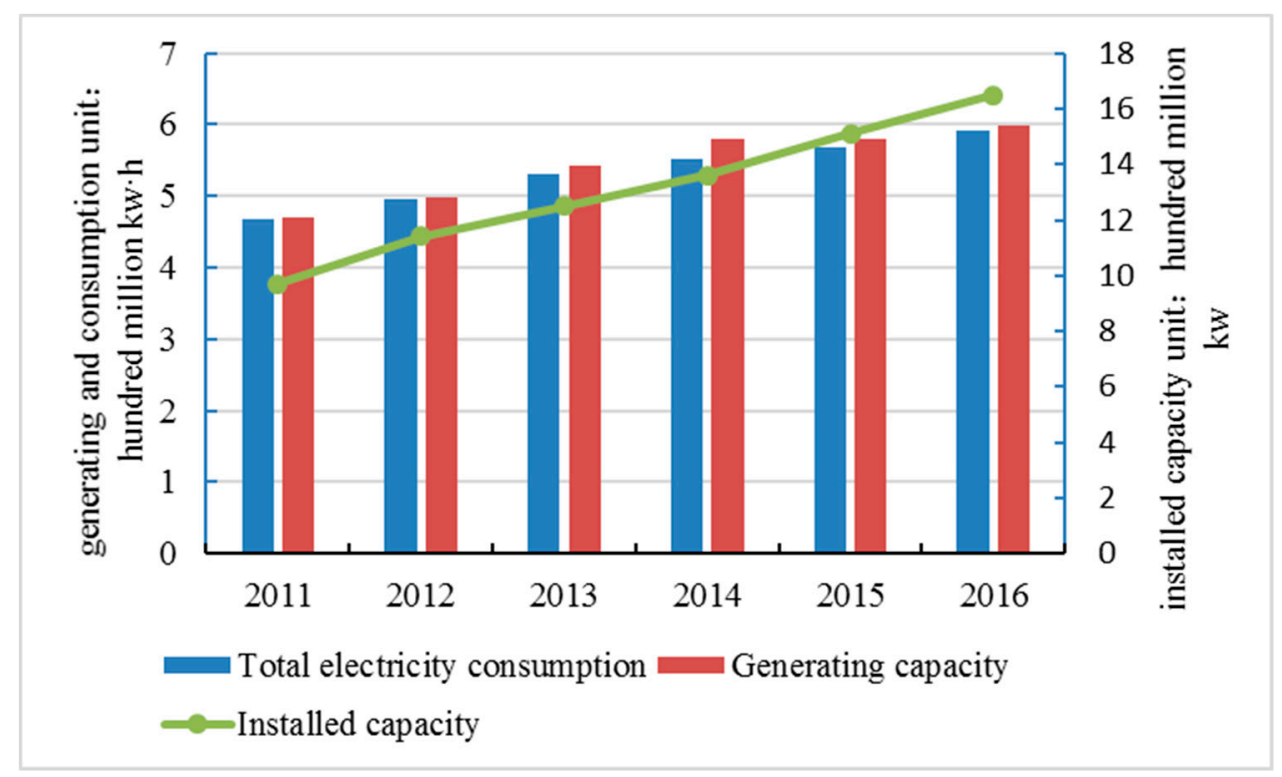

Figure 1. Production and consumption related data of electric power industry. 


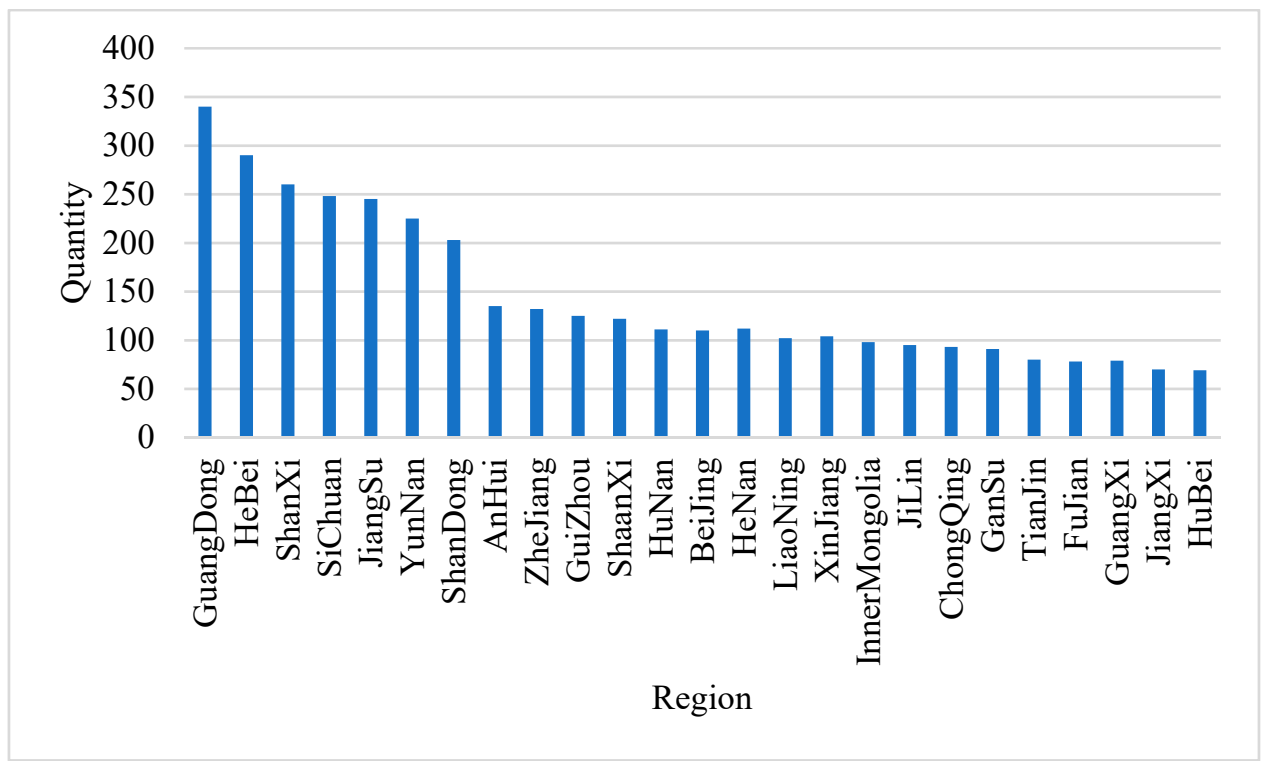

Figure 2. Number of registered electric power sale companies in major regions of China.

Table 1. Electricity market liberalization schedule in China.

\begin{tabular}{cl}
\hline Stage & \multicolumn{1}{c}{ Object } \\
\hline Stage 1 & $\begin{array}{l}\text { All industrial and commercial electricity users with voltage level higher than } 110 \mathrm{kV} \\
(66 \mathrm{kV}) \\
\text { Part of industrial and commercial electricity users with voltage level higher than } 35 \mathrm{kV}\end{array}$ \\
\hline Stage 2 & $\begin{array}{l}\text { All industrial and commercial electricity users with voltage level higher than } 35 \mathrm{kV} \\
\text { Part of industrial and commercial electricity users with voltage level higher than } 10 \mathrm{kV}\end{array}$ \\
\hline Stage 3 & All electricity users with voltage level higher than $10 \mathrm{kV}$ \\
\hline
\end{tabular}

The remainder of the paper is organized as follows. Section 2 summarizes the relevant literature. Section 3 constructs the CGE model for Chinese economy and electricity sector. Section 4 presents assumptions and results associated with the simulations. Section 5 proceeds with the discussion of the policy implications stemming from results of the modelling.

\section{Literature Review}

Computable general equilibrium (CGE) models can be applied to measure sector- and economy-wide effects of (shifts in) regulation and the economic situation in general. The theoretical foundation of the CGE model rests on the Warlas's general equilibrium theory, which describes a cyclical economic process as follows: Production generates income, income triggers demand, demand further induces production and the quantities and prices of goods marketed vary until demand and supply are balanced in the economic system (i.e., equilibrium is reached). The model originates from the 1960s and has been widely applied in the areas of global trade [9,10], environmental protection [11,12], economic policy reform [13] and tax reform [14].

Indeed, the CGE models can also focus on the energy sector and thus quantify the effects of external and internal factors there. Scaramucci et al. [15] used a CEG model to estimate the economic impacts of constraining the supply of electric energy in Brazil. Hosoe [16] simulated the liberalization of electricity market in Japan with a CGE model. Akkemik and Oguz [17] examined potential outcomes of full liberalization policy on efficiency and competition in the Turkish electricity market by means of an applied computable general equilibrium model and the counter-factual simulation. Rodrigues and Linares $[18,19]$ used a CGE model to assess the impacts of a Demand Response program in the Spanish electricity market. Hwang and Lee [20] looked into the shifts within the Korean 
electricity market by using a CGE model. Farajzadeh and Bakhshoodeh [21] analysed economic and environmental consequences of the phasing out of energy subsidies in Iran by employing a CGE model. Capros et al. [22] focused on the macroeconomic and sector-level effects induced by changes in electricity and gas prices in the EU by means of a CGE model. Bataille and Melton [23] applied a CGE model to estimate the impacts of energy efficiency improvements in Canada by considering indicators related to GDP, employment, economic structure for the period of 2002-2012. Melnikov et al. [24] applied the dynamic CGE model to appraise the effects of carbon taxes on household consumption and carbon emissions. Mu et al. [25] modelled the possible reductions in global greenhouse gas emission following the Paris Agreement by means of a CGE model. Therefore, the applications of CGE models are versatile in terms of geographical area, level of aggregation, and factors covered.

Due to the reform of China's economic system and the lack of statistical data, the studies applying a general equilibrium model appeared at a relatively late stage in China. However, there have been recent applications of CGE models for Chinese economy. Liu et al. [26] applied an environmentally extended CGE model to assess environmental and economic impacts of the new emission standard for thermal power plants. Li et al. [27] construct a dynamic CGE model to explore the impacts of EVs and CCS respectively on China's economics, environmental quality and energy demand based on the six simulation scenarios. Zhang et al. [28] applied CGE and a social accounting matrix for 2012 to analyse the impacts of the natural gas industry reform in China. Zhang et al. [29] utilized CGE models to assess the outcomes of the inclusion of different fuel types (shale gas and non-grain bioethanol) in the energy-mix. Liu et al. [30] employed a CGE methodology to quantify the outcomes of implementation of the fuel economy requirements for vehicles in China in the sense of economy and environment. Similarly, the effects on the different dimensions of sustainability arising due to the possible expansion of the bioethanol production were analysed by Ge and Lei [31] via CGE modelling. Xiao et al. [32] proposed a modified CGE model for China incorporating risk analysis for identifying the prospective pathways for promotion of the renewables. Liu and Zhou [33] applied a CGE model to explore the impact of a $5 \%$ ad valorem coal resource tax on the Chinese economy under four scenarios involving distinguished electricity pricing mechanisms and a tax revenue recycling scheme by deducting consumption tax.

However, the applications of CGE modelling on Chinese power sector are rather limited. Yang and Cui [34] established a CGE model with 39 sectors which subdivides the power sector into coal-fired, hydropower, nuclear, gas-fired and oil-fired generation. The model was applied to analyse the impact of replacing coal-fired power generation technology with gas-fired power generation technology on the economy, power generation and pollutant emissions in China. Zhang [35] analysed the linkages between electricity price and industrial structure in China by means of a CGE model. The results showed that though the impact of price changes on the output was very low across industries, the ones featuring higher electricity consumption appeared to be more sensitive to changes in electricity price. Tan et al. [36] constructed a CGE model to analyse the impacts of exchange rate change on electric power industry. Following the declines in the exchange rate of RMB by $1 \%$ and $3 \%$, both industrial and household electricity consumption is expected to go down, with a more important impact on the electricity-intensive sectors. He et al. [37] set up a CGE model to analyse the impacts of changes in coal price on the electric power industry and the impacts of adjustments in electricity price on the macro-economic situation in China. The latter study showed the electricity price increase exerts an adverse influence on the total output, GDP, and the CPI. Song and Cui [38] employed a dynamic CGE model for China (CDECGE) to quantify the effects of the electricity market reform in China. The results showed that reform is likely to be desirable in the sense of the targets regarding energy savings and mitigation of carbon emissions.

However, the abovementioned studies only discussed the impact of electricity price change without breaking down the electricity industry into sub-sectors to discuss the impact of deregulation on different parts of the power supply chain. The latter issue is particularly important when assessing the outcomes of the different stages of the electricity market reform that are likely to have different 
impacts on different sub-sectors. We address this literature gap by estimating the potential impacts of electricity market reform by employing a more detailed CGE model.

In order to analyse the impacts of liberalization on the industries with respect to different scopes of the electricity market reform, we set up an electricity and economy CGE model. Contrasted with the earlier literature, we break down the electricity sector into the three sub-sectors (generation, transmission and distribution) in this study. It should be noted that, under the complete competition model, the power sector should be divided into four sub-sectors: power generation, transmission, distribution and retail sales. Due to the lack of relevant data on the retail sale side, it is assumed that the distribution and retail sale of electricity will comprise an integral part of the market.

The present study, therefore, contributes to literature in a number of ways. First, the impacts of electricity regulatory reforms in China are assessed. This provides a piece of evidence on the economic effects of such reforms. These findings might be important when shaping regulatory reforms in different countries. Second, the application of a CGE model offers a contribution to literature on economic modelling and identifies possible directions for further research in the area both in China and internationally. Third, the application of a CGE model in the case of electricity market reform might provide guidelines for similar applications in other sectors and regions.

\section{The CGE Model for Chinese Electricity and Economy Sector}

In this section, we set up a CGE model for the analysis of the deregulation of China's electricity market. We briefly discuss the major constructing modules of the model. The linkages among the different modules are also discussed.

\subsection{Production Module}

The production module describes the transformation of inputs into output, i.e. the process of domestic production. Figure 3 shows the structure of the production side. In CGE models, the Cobb-Douglas production function, Leontief production function and the constant elasticity of substitution (CES) type production function are commonly used.

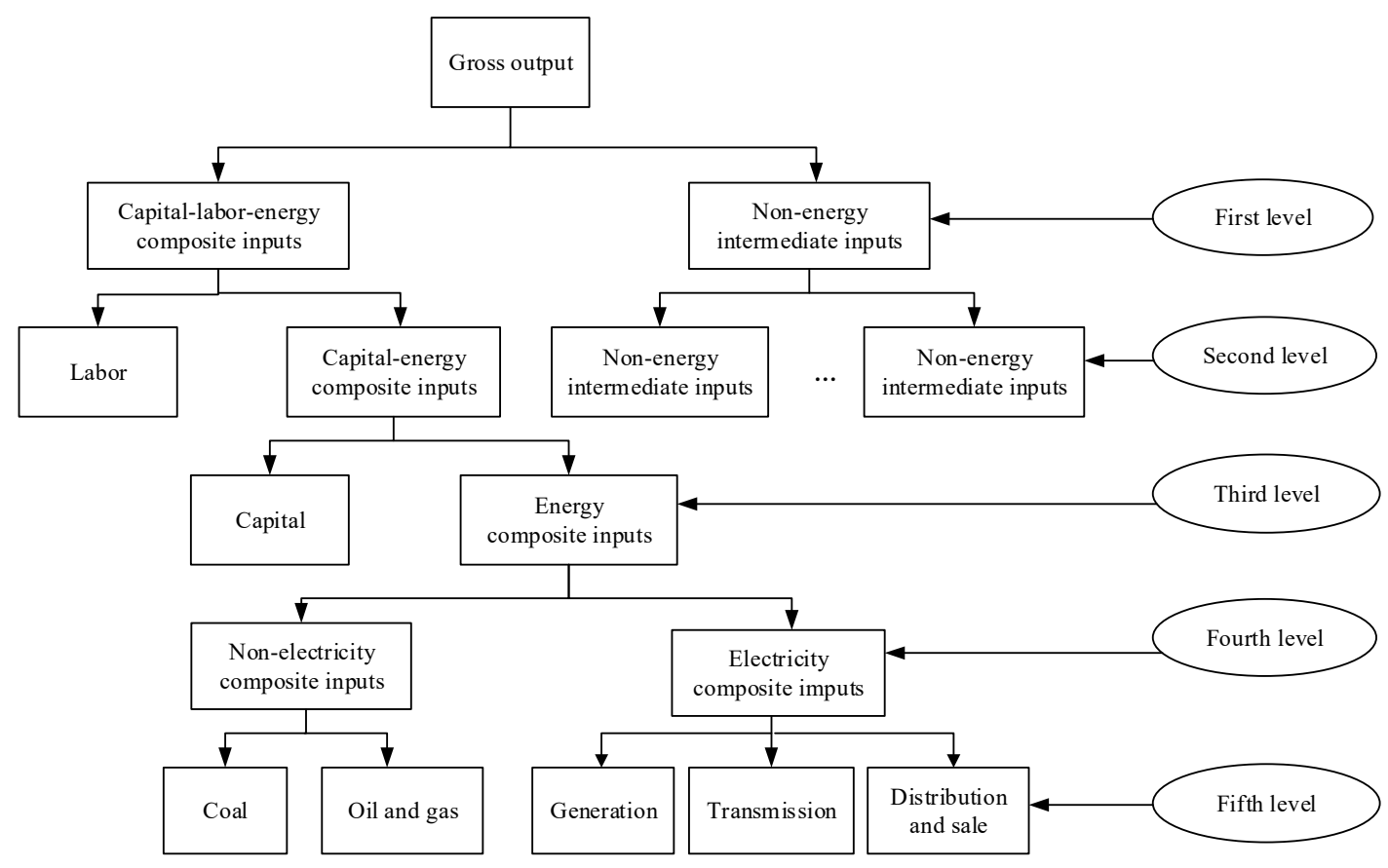

Figure 3. Production structure of the CGE model.

In this paper, we assumed a CES type function for modelling the productive technology, and the level of output of each sector was determined to ensure market equilibrium. The model basically 
covered the five levels. At each level, the degree of substitution was defined via the elasticity of substitution. At the highest level of aggregation, we considered (substitutability between) composite energy-related input and composite non-energy input, thus modelling substitutability among energy and non-energy inputs. For the energy production sectors, such as coal, OG (Oil and gas) and electricity generation, we assumed that the energy intermediate inputs cannot be replaced, and the energy intermediate inputs were free to be replaced for the other sectors. As for the factor market, we assumed that capital and labour can replace each other in the capital market when the relative factor prices change. We further assumed that capital is fixed in all industries, whereas labour is completely mobile across sectors. In addition, we assumed that each activity produces one commodity and lower-case indexes $a$ and $c$ denote activities and commodities, respectively. Please refer to Tables 2-11 for the notations of variables and parameters used in the model.

At the first level, the gross output $Q A$ was modelled as a CES function of capital-energy-labour composite input (Equations (1)-(3)) and non-energy intermediate input (Equations (4) and (5)) with the latter input being defined in terms of Leontief input-output relations. The characteristic of the Leontief function is zero elasticity of substitution between intermediate inputs which implies the input coefficient is fixed.

$$
\begin{gathered}
Q A_{a}=\alpha_{a}^{A} \cdot\left(\delta_{a}^{A} \cdot Q K E L_{a}^{\rho^{A}}+\left(1-\delta_{a}^{A}\right) \cdot Q N D_{a}^{\rho^{A}}\right)^{1 / \rho^{A}} \\
\frac{P K E L_{a}}{P N D_{a}}=\frac{\delta_{a}^{A}}{1-\delta_{a}^{A}} \cdot\left(\frac{Q N D_{a}}{Q K E L_{a}}\right)^{1-\rho^{A}} \\
P A_{a} \cdot Q A_{a}=P K E L_{a} \cdot Q K E L_{a}+P N D_{a} \cdot Q N D_{a} \\
U N D_{c, a}=\alpha_{c, a} \cdot N D_{a} \\
P N D_{a}=\sum_{c} \alpha_{c, a} \cdot P Q_{c}
\end{gathered}
$$

At the lower level of aggregation, the capital-energy-labour composite input is specified by a CES function of labour and capital-energy composite inputs (Equations (6)-(8)):

$$
\begin{gathered}
Q K E L_{a}=\alpha_{a}^{K E L} \cdot\left(\delta_{a}^{K E L} \cdot Q K E_{a}^{\rho^{K E L}}+\left(1-\delta_{a}^{K E L}\right) \cdot Q L_{a}^{\rho^{K E L}}\right)^{1 / \rho^{K E L}} \\
\frac{P K E_{a}}{P L_{a}}=\frac{\delta_{a}^{K E L}}{1-\delta_{a}^{K E L}} \cdot\left(\frac{Q L_{a}}{Q K E_{a}}\right)^{1-\rho^{K E L}} \\
P K E L_{a} \cdot Q K E L_{a}=P K E_{a} \cdot Q K E_{a}+P L_{a} \cdot Q L_{a}
\end{gathered}
$$

At the bottom three levels, we distinguished the capital-energy composite inputs (Equations (9)-(11)), energy composite inputs (Equations (12)-(14)) and non-electricity composite inputs (Equations (15)-(17)) by CES functions:

$$
\begin{gathered}
Q K E_{a}=\alpha_{a}^{K E} \cdot\left(\delta_{a}^{K E} \cdot Q K_{a}^{\rho^{K E}}+\left(1-\delta_{a}^{K E}\right) \cdot Q E C_{a}^{\rho^{K E}}\right)^{1 / \rho^{K E}} \\
\frac{P K_{a}}{P E C_{a}}=\frac{\delta_{a}^{K E}}{1-\delta_{a}^{K E}} \cdot\left(\frac{Q E C_{a}}{Q K_{a}}\right)^{1-\rho^{K E}} \\
P K E_{a} \cdot Q K E_{a}=P K_{a} \cdot Q K_{a}+P E C_{a} \cdot Q E C_{a} \\
Q E C_{a}=\alpha_{a}^{E C} \cdot\left(\delta_{a}^{E C} \cdot Q E L E C N_{a}^{\rho^{E C}}+\left(1-\delta_{a}^{E C}\right) \cdot Q E L E C_{a}^{\rho^{E C}}\right)^{1 / \rho^{E C}} \\
\frac{P E L E C N_{a}}{P E L E C_{a}}=\frac{\delta_{a}^{E C}}{1-\delta_{a}^{E C}} \cdot\left(\frac{Q E L E C_{a}}{Q E L E C N_{a}}\right)^{1-\rho^{E C}}
\end{gathered}
$$




$$
\begin{gathered}
P E C_{a} \cdot Q E C_{a}=P E L E C N_{a} \cdot Q E L E C N_{a}+P E L E C_{a} \cdot Q E L E C_{a} \\
Q E L E C N_{a}=\alpha_{a}^{E L E C N} \cdot\left(\delta_{a}^{E L E C N} \cdot Q O G_{a}^{\rho^{E L E C N}}+\left(1-\delta_{a}^{E L E C N}\right) \cdot Q C O A L_{a}^{\rho E L E C N}\right)^{1 / \rho^{E L E C N}} \\
\frac{P O G_{a}}{P C O A L_{a}}=\frac{\delta_{a}^{E L E C N}}{1-\delta_{a}^{E L E C N}} \cdot\left(\frac{Q C O A L_{a}}{Q O G_{a}}\right)^{1-\rho^{E L E C N}} \\
P E L E C N_{a} \cdot Q E L E C N_{a}=P O G_{a} \cdot Q O G_{a}+P C O A L_{a} \cdot Q C O A L_{a}
\end{gathered}
$$

Although this paper divides the electric power industry into three sub-sectors-power generation, transmission and distribution-the three sub-sectors follow vertically integrated structure and there was no substitution relationship for the electricity composite functions. That is, the total output of the power sector is the total output of the power generation sector, which will be delivered to the end user through the transmission and distribution network. The specific equations will be given in Section 4.3. Tables 2 and 3 present the variables and parameters of the production model, respectively.

Table 2. Variables for the production module.

\begin{tabular}{ll}
\hline Variable & Variable Definition \\
\hline$P A_{a}$ & Price of sector output \\
$P C O A L_{a}$ & Price of coal input \\
$P E C_{a}$ & Price of energy composite input \\
$P E L E C_{a}$ & Price of electricity composite input \\
$P E L E C N_{a}$ & Price of non-electricity composite input \\
$P K_{a}$ & Price of capital input \\
$P K E L_{a}$ & Price of capital-energy-labour composite input \\
$P K E_{a}$ & Price of capital-energy composite input \\
$P L_{a}$ & Price of labour input \\
$P N D_{a}$ & Price of non-intermediate input \\
$P O G_{a}$ & Price of oil and gas composite input \\
$Q A_{a}$ & Quantity of sector output \\
$Q C O A L_{a}$ & Quantity of coal input \\
$Q E C_{a}$ & Quantity of energy composite input \\
$Q E L E C_{a}$ & Quantity of electricity composite input \\
$Q E L E C N_{a}$ & Quantity of non-electricity composite input \\
$Q K_{a}$ & Quantity of capital input \\
$Q K E_{a}$ & Quantity of capital-energy composite input \\
$Q K E L_{a}$ & Quantity of capital-energy-labour composite input \\
$Q L_{a}$ & Quantity of labour input \\
$Q N D_{a}$ & Quantity of non-energy intermediate input \\
$Q O G_{a}$ & Quantity of oil and gas composite input \\
$U N D_{c, a}$ & Quantity of the unit intermediate input \\
\hline
\end{tabular}

Table 3. Parameters for the production module.

\begin{tabular}{ll}
\hline Parameter & Parameter Definition \\
\hline$\alpha_{c, a}$ & Direct consumption coefficient of intermediate input \\
$\delta_{a}^{A}$ & Share parameter of CES function of $Q A$ \\
$\alpha_{a}^{A}$ & Scale parameter of CES function of $Q A$ \\
$\rho^{A}$ & Substitution elasticity parameter of CES function of $Q A$ \\
$\delta_{a}^{K E L}$ & Share parameter of CES function of $K E L$ \\
$\alpha_{a}^{K E L}$ & Scale parameter of CES function of $K E L$ \\
$\rho^{K E L}$ & Substitution elasticity parameter of CES function of $K E L$ \\
$\delta_{a}^{K E}$ & Share parameter of CES function of $K E$ \\
\hline
\end{tabular}


Table 3. Cont.

\begin{tabular}{ll}
\hline Parameter & Parameter Definition \\
\hline$\alpha_{a}^{K E}$ & Scale parameter of CES function of $K E$ \\
$\rho^{K E}$ & Substitution elasticity parameter of CES function of $K E$ \\
$\delta_{a}^{E C}$ & Share parameter of CES function of $E C$ \\
$\alpha_{a}^{E C}$ & Scale parameter of CES function of $E C$ \\
$\rho^{E C}$ & Substitution elasticity parameter of CES function of $E C$ \\
$\delta_{a}^{E L E C N}$ & Share parameter of CES function of $E L E C N$ \\
$\alpha_{a}^{E L E C N}$ & Scale parameter of CES function of $E L E C N$ \\
$\rho^{E L E C N}$ & Substitution elasticity parameter of CES function of $E L E C N$ \\
\hline
\end{tabular}

\subsection{Trade Module}

The CGE model assumes that China acts as a "small country", i.e., the world prices are exogenously determined. Equations (18) and (19) define the domestic imports and exports prices, respectively:

$$
\begin{aligned}
P E_{a} & =p w e_{a} \cdot E X R \\
P M_{c} & =p w m_{c} \cdot E X R
\end{aligned}
$$

The trade module covers three categories of goods: Domestic output to exports $(Q E)$, domestic output to domestic market $(Q D)$ and imports supply to the domestic market $(Q M)$. The total output of domestic production $(Q A)$ is composed of $Q E$ and $Q D$, while domestic market demand $(Q Q)$ is composed of $Q M$ and $Q D$, the specific relationship is shown in Figure 4.

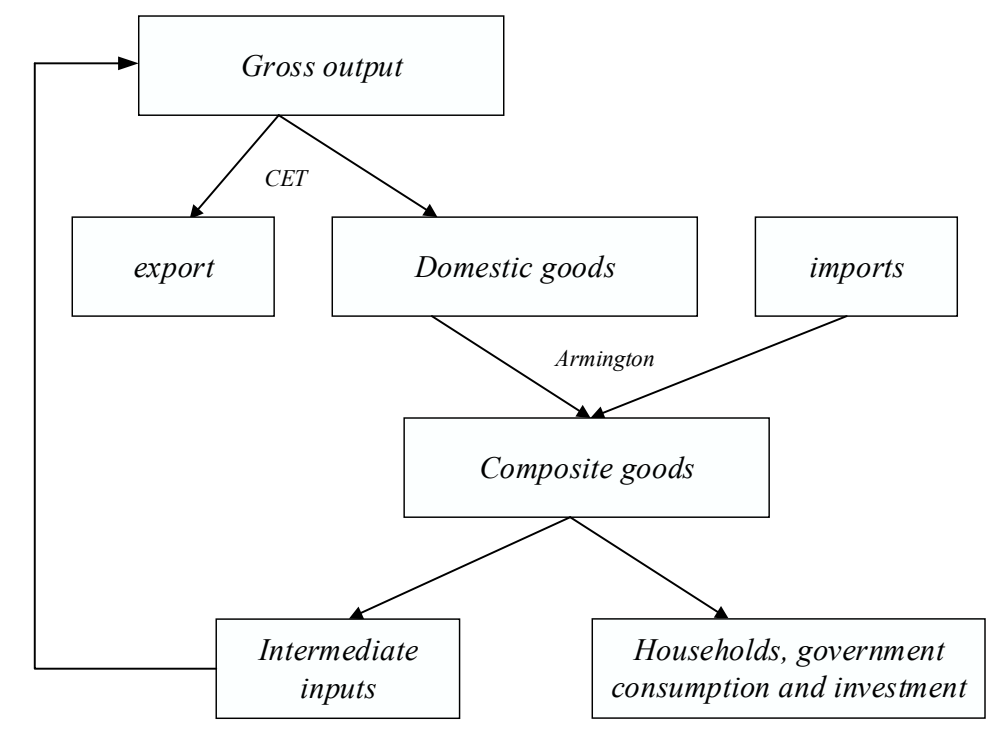

Figure 4. Trade structure of the CGE model.

In order to maximize profit, the domestic commodity producers optimize the combination of $Q E$ and $Q D$. Specifically, the assignment of the output for domestic and export markets is described by the constant elasticity of transformation (CET) functions (Equations (20)-(22)):

$$
\begin{gathered}
Q A_{a}=\alpha_{a}^{q a} \cdot\left(\delta_{a}^{q a} \cdot Q D_{a}^{\rho^{q a}}+\left(1-\delta_{a}^{q a}\right) \cdot Q E_{a}^{\rho^{q a}}\right)^{1 / \rho^{q a}} \\
\frac{P D_{a}}{P E_{a}}=\frac{\delta_{a}^{q a}}{1-\delta_{a}^{q a}} \cdot\left(\frac{Q E_{a}}{Q D_{a}}\right)^{1-\rho^{q a}} \\
P A_{a} \cdot Q A_{a}=P D_{a} \cdot Q D_{a}+P E_{a} \cdot Q E_{a}
\end{gathered}
$$


Similarly, while purchasing goods, consumers seek to optimize the combination of domestic and imported goods. Specifically, the assignment of expenditures for the latter two categories of goods is described by the CES function (Equations (23)-(25)), known as the Armington function:

$$
\begin{gathered}
Q Q_{c}=\alpha_{c}^{q q} \cdot\left(\delta_{c}^{q q} \cdot Q D_{c}^{\rho^{q q}}+\left(1-\delta_{c}^{q q}\right) \cdot Q M_{c}^{\rho_{c}^{q q}}\right)^{1 / \rho^{q q}} \\
\frac{P D_{c}}{P M_{c}}=\frac{\delta_{c}^{q q}}{1-\delta_{c}^{q q}} \cdot\left(\frac{Q M_{c}}{Q D_{c}}\right)^{1-\rho^{q q}} \\
P Q_{c} \cdot Q Q_{c}=P D_{c} \cdot Q D_{c}+P M_{c} \cdot Q M_{c}
\end{gathered}
$$

Please see Tables 4 and 5 for the variables and parameters for the trade module, respectively.

Table 4. Variables for the trade module.

\begin{tabular}{cc}
\hline Variable & Variable Definition \\
\hline$P M_{c}$ & Price of import commodities \\
$P E_{c}$ & Price of export commodities \\
$E X R$ & Exchange rate \\
$P Q_{c}$ & Price of domestic demand commodities \\
$P D_{c}$ & Price of domestic supply commodities \\
$Q Q_{c}$ & Quantity of domestic demand commodities \\
$Q D_{c}$ & Quantity of domestic supply commodities \\
$Q M_{c}$ & Quantity of import commodities \\
$Q E_{c}$ & Quantity of export commodities \\
$p w e_{a}$ & Import price in current units \\
$p w e_{c}$ & Export price in current units \\
\hline
\end{tabular}

Table 5. Parameters for the trade module.

\begin{tabular}{cc}
\hline Parameter & Parameter Definition \\
\hline$\delta_{a}^{q a}$ & Share parameter of CET function \\
$\alpha_{a}^{q a}$ & Scale parameter of CET function \\
$\rho^{E C}$ & Substitution elasticity parameter of CET function \\
$\delta_{c}^{q q}$ & Share parameter of Armington function \\
$\alpha_{c}^{q q}$ & Scale parameter of Armington function \\
$\rho^{q q}$ & Substitution elasticity parameter of Armington function \\
\hline
\end{tabular}

\subsection{Income Module}

The income generated in production is allocated across three main institutions: Households, enterprises and government. The income of households is mainly composed of labour income, investment income and transfer payments. Tables 6 and 7 present the variables and parameters for the income module, respectively. In the paper, we followed the assumption that all the transfers among the rest of the world and government, enterprise and related factors are fixed sums expressed in foreign currency, whereas other transfer payments are defined as fixed proportions of income:

$$
Y H=P L \cdot Q L+P K \cdot Q K \cdot \text { shif }_{h}+\operatorname{trans} r_{h, g o v}+\operatorname{trans} f r_{h, \text { ent }}+\operatorname{trans} r_{h, \text { row }}
$$


Table 6. Variables for the income module.

\begin{tabular}{ll}
\hline Variable & Variable Definition \\
\hline$Y H$ & Household income \\
$Y G$ & Government income \\
$Y E$ & Enterprise income \\
MTAX & Import tax \\
ATAX & Export tax \\
transfr & Production tax \\
transfr & Transfer from government to the household \\
transfr & Transfer from enterprise to the household \\
Transfr $r_{\text {gov, row }}$ & Transfer from the rest of the world to the household \\
\hline
\end{tabular}

Table 7. Parameters for the income module.

\begin{tabular}{ll}
\hline Parameter & Parameter Definition \\
\hline$s h i f_{h}$ & Proportion of household capital income \\
shif $f_{\text {ent }}$ & Proportion of enterprise capital income \\
$t i_{h}$ & Personal income tax rate \\
$t i_{\text {ent }}$ & Corporate income tax rate \\
\hline
\end{tabular}

The government collects taxes and receives transfers from the rest of the world. Tax revenue consists of individual income tax, export tax, import tax, the enterprise income tax and production tax.

$$
Y G=t i_{h} \cdot Y H+M T A X+E T A X+A T A X+t i_{\text {ent }} \cdot Y E+\text { transfrgov,row }
$$

The capital income of enterprises is defined as:

$$
Y E=W K \cdot Q K \cdot s h i f_{\text {ent }}
$$

\subsection{Expenditure Module}

Following Equation (29), households allocate disposable income for consumption and savings, where savings are defined as a fixed share of income. The government revenue is mainly used for transfer payments, commodity consumption and government savings. Government transfer payments to households and enterprises are defined as a fixed proportion of income, while the proportion of government consumption on goods $\left(\overline{Q G}_{c}\right)$ is fixed (Equations (30) and (31)). Enterprise income is allocated to taxes, savings, and transfers to the households (Equations (32) and (33)). The variables and parameters used in the consumption module are presented in Tables 8 and 9, respectively.

$$
\begin{gathered}
E H=\left(1-t i_{h}\right) \cdot Y H-H S A V=\left(1-m p s_{h}\right) \cdot\left(1-t i_{h}\right) \cdot Y H \\
E G=\sum_{c} Q G_{c} \cdot P Q_{c}+{\text { trans } f r_{h, g o v}+\text { trans }_{\text {row }, \text { gov }}} \\
Y G=E G+G S A V \\
E E=t i_{\text {ent }} \cdot Y E+\text { transfr }_{h, \text { ent }} \\
Y E=E E+E S A V
\end{gathered}
$$


Table 8. Variables for the consumption module.

\begin{tabular}{cl}
\hline Variable & Variable Definition \\
\hline$E H$ & Household expenditures \\
$E G$ & Government expenditures \\
$E E$ & Enterprise expenditures \\
$H S A V$ & Household savings \\
$G S A V$ & Government savings \\
$E S A V$ & Enterprise savings \\
transfr $_{\text {row, gov }}$ & Transfer from government to the rest of the world \\
\hline
\end{tabular}

Table 9. Parameter for the consumption module.

\begin{tabular}{cc}
\hline Parameter & Parameter Definition \\
\hline$m p s_{h}$ & Household savings ratio coefficient \\
\hline
\end{tabular}

\subsection{Macroeconomic Closure}

Macroeconomic Closure is a special structure formed on the basis of macroeconomic theory, including the choice of function types, the setting of endogenous and exogenous variables. Different types of closure are referred to given the corresponding macroeconomic theories. The paper adopts the neoclassical macro closure conditions which corresponds to China's economic development mode. The associated variables are presented in Table 10.

The CGE model considered the four macroeconomic balances: The factor market balance, the commodity market balance, the current-account balance and the savings-investment balance. In the factor markets, equilibrium requires full employment of the labour force and full utilisation of capital, i.e., the aggregate demand of is equal to the total supply of each sector. Furthermore, the supply variable $Q L S$ and $Q K S$ are assumed to be fixed:

$$
\begin{aligned}
& \sum_{a} Q L_{a}=Q L S \\
& \sum_{a} Q K_{a}=Q K S
\end{aligned}
$$

In the commodity market, Equation (36) implies that the aggregate demand is equal to the aggregate supply. Among the elements of the aggregate supply, the quantity of investment $\left(\overline{Q I N V_{c}}\right)$ is exogenous:

$$
Q Q_{c}=\sum_{a} Q I N T_{c, a}+Q H_{c}+Q I N V_{c}+Q G_{c}+q u s t o_{c}
$$

In current-account balance (Equation (37)), we chose such a closure rule that the exchange rate $(E X R)$ was treated as an endogenous variable, while foreign savings enters the model as an exogenous variable $(\overline{F S A V})$ :

$$
\begin{aligned}
& \sum_{c} p w m_{c} \cdot Q M_{c}+\operatorname{trans}_{\text {row }, f}+\text { transfr }_{\text {row }, \text { gov }} \\
& =\sum_{c} p w e_{c} \cdot Q E_{c}+\text { transf }_{h, \text { row }}+\text { transf } r_{\text {gov, row }}+F S A V \text {. }
\end{aligned}
$$

Equation (38) states that total saving and total investment have to be equal. In order to maintain the equality between the variables and equations, we added variable WALRAS to Equation (38). The solution value of WALRAS should be zero. Besides, we include Equation (39) in the model to analyse the impact of policy changes on GDP.

$$
\begin{aligned}
& H S A V+G S A V+F S A V \cdot E X R+E S A V= \\
& =\sum_{c} P Q_{c} \cdot Q I N V_{c}+\sum_{c} P Q_{c} \cdot q u s t t_{c}+W A L R A S .
\end{aligned}
$$




$$
\begin{aligned}
& G D P=\sum_{c} P Q_{c} \cdot\left(Q H_{c}+Q G_{c}+Q I N V_{c}+q u s t_{c}\right) \\
& +\sum_{c} P E_{c} \cdot Q E_{c}-\sum_{c} p w m_{c} \cdot E X R \cdot Q M_{c} .
\end{aligned}
$$

Table 10. Variables for the equilibrium module.

\begin{tabular}{cl}
\hline Variable & Variable Definition \\
\hline$Q L S$ & Total supply of labour \\
$Q K S$ & Total supply of capital \\
$Q I N T_{c, a}$ & Quantity of intermediate input \\
$\operatorname{QINV}_{c}$ & Quantity of investments \\
transfr $_{\text {row }, f}$ & Foreign capital investment returns \\
QUSTO & Stock change \\
WALRAS & Balanced slack variable \\
GDP & Gross domestic product \\
\hline
\end{tabular}

\subsection{Welfare Block}

Analysis of the effects of public policy on social welfare can be based on multiple different indicators. Among these, Hicksian equivalent variation is rather common. In this paper, we considered Hicksian equivalent variation as a measure of the effect of the external policy on the households' social welfare. In Equation (40), EV greater than zero implies that the implementation of policies enhanced the welfare of households:

$$
E V=\sum_{a} P Q_{a}^{o} \cdot\left(Q H_{a}-Q H_{a}^{o}\right)
$$

Please see Table 11 for the variables used in the welfare module.

Table 11. Variables for the resident welfare module.

\begin{tabular}{cc}
\hline Variable & Variable Definition \\
\hline$E V$ & Hicksian equivalent variation \\
$E\left(U^{s}, P Q^{b}\right)$ & The level of effectiveness after implementation of policies \\
$E\left(U^{b}, P Q^{b}\right)$ & The level of effectiveness before implementation of policies \\
\hline
\end{tabular}

\section{Policy Simulation}

This section presents the basic assumptions for different scenarios defining electricity market liberalisation in China. The results of the simulation are then presented. The effects on different agents and sectors are discussed.

\subsection{Social Accounting Matrix}

Social accounting matrix (SAM) was the basic data set underlying the CGE model. It represents the system of national accounts in matrix form. The SAM applied in this paper was based on the 2012 input-output tables for China which were issued by the National Bureau of Statistics in 2016. The other data for the SAM came from China's Statistical Yearbook, China's Fiscal Yearbook, China's Electric Power Yearbook, China's Tax Yearbook, and China's Customs Statistical Yearbook. According to the needs of the research, we reorganized the 42 sectors in the input-output tables into 11 sectors (see Table 12). In addition, the institutional accounts included government, enterprises, a representative household, and the factor accounts including capital and labour in the micro-SAM. The main purpose of this paper is to simulate the impact of liberalisation of electricity market, so there is no further disaggregation of household accounts. 
Table 12. Sectors covered by the CGE model and the corresponding notations.

\begin{tabular}{cccc}
\hline Number & Sectors & $\begin{array}{c}\text { Sector Codes in the } \\
\text { Input-Output Tables }\end{array}$ & Abbreviations \\
\hline 1 & agriculture & 1 & agr \\
2 & coal mining & 2 & coal \\
3 & oil, gas, refined oil & 03,11 & OG \\
4 & products & & mining \\
5 & other mining & 04,05 & elec-G \\
6 & electricity generation & 25 & elec-T \\
7 & electricity transmission & 25 & elec-D \\
8 & manufacturing & 25 & man \\
9 & construction & $06-10,12-22$ & cons \\
10 & financial services & 28 & serv \\
11 & public utilities & $23,24,26,27,29-34$ & pub \\
\hline
\end{tabular}

Due to the lack of data availability, the initial SAM did not balance the sums of rows and columns. The two approaches are often applied to circumvent this issue (the RAS method and cross-entropy method). In this paper, we applied the cross-entropy method to balance the SAM. Table 13 presents the macro-SAM for 2012.

The electricity sector in CGE model is divided into three sectors: Power generation, transmission and distribution. Note that the latest I-O table contains only the relevant data of electricity, heat production and supply. Therefore, we needed to decompose the data for power sector when compiling the micro-SAM table.

First of all, compared with the production and supply of electric power, the production and supply of heat is a very small sector. Accordingly, we did not decompose the relevant variables, but directly use them to describe the production and supply of electric power. Secondly, we built our model on the assumption that the transmission sector takes the output of the power sector as the sole intermediate input, and the distribution sector, in turn, receives the output of the transmission sector as the only input (Akkenik, Oguz, 2011). The output of the distribution sector is then electricity sales to the end-users. 
Table 13. The macro-SAM table of China in 2012 (Unit: Billion).

\begin{tabular}{|c|c|c|c|c|c|c|c|c|c|c|}
\hline & Commodities & Activities & Factors & Households & Enterprises & Government & Row & Capital Account & qusto & Total \\
\hline Commodities & & 1,162,399 & & 198,537 & & 73,182 & 136,666 & 237,751 & 30,277 & $1,838,812$ \\
\hline Activities & $1,699,199$ & & & & & & & & & $1,699,199$ \\
\hline Factors & & 463,194 & & & & & & & & 463,194 \\
\hline Households & & & 288,471 & & 31,536 & 14,764 & 401 & & & 335,172 \\
\hline Enterprises & & & 172,503 & & & & & & & 172,503 \\
\hline Government & 17,586 & 73,606 & & 5820 & 43,115 & & -190 & 77,566 & & 217,503 \\
\hline Row & 122,027 & & 2220 & & & 149 & & & & 124,396 \\
\hline Capital Account & & & & 130,815 & 97,852 & 129,408 & $-12,481$ & & & 345,594 \\
\hline qusto & & & & & & & & 30,277 & & 30,277 \\
\hline Total & $1,838,812$ & 1,699,199 & 463,194 & 335,172 & 172,503 & 217,503 & 124,396 & 345,594 & 30,277 & \\
\hline
\end{tabular}




\subsection{Parameter Calibration}

The CGE model involved two kinds of parameters: Some could be calibrated by applying production functions (Section 3.1) and basic data, while the others had to be determined exogenously. The latter parameters contained the share parameter, scale parameter, tax rate and transfer payments. The former parameters contained the production factors substitution elasticity, Armington elasticity, and CES elasticity. The parameters can be acquired by econometric methods or literature research. Based on the earlier literature $[39,40]$ and making appropriate adjustments, we obtained the parameter values used in this paper (Table 14).

Table 14. Substitution elasticity parameters used in CGE model.

\begin{tabular}{ccccccccc}
\hline sectors & agr & coal & OG & min & elec & man & con & pub \\
\hline$\varepsilon^{E C}$ & 0.7 & 0 & 0 & 0.7 & 0 & 0.7 & 0.7 & 0.7 \\
$\varepsilon^{E L E C N}$ & 1.25 & 0 & 0 & 1.25 & 0 & 1.25 & 1.25 & 1.25 \\
$\varepsilon^{q q}$ & 2.2 & 3 & 3 & 3 & 0.9 & 3 & 2 & 1.9 \\
$\varepsilon^{q a}$ & 5 & 4 & 4 & 4 & 0.5 & 4.6 & 4 & 3.2 \\
\hline
\end{tabular}

\subsection{Counter-Factual Scenarios}

Opinions Regarding the Deepening of the Power Sector's Reform pointed out that the reform should maintain a relatively stable electricity price for households, agriculture and public utilities. We carried out two kinds of simulations, assuming different scenarios for the scope of the reform of the Chinese electric power market. In Simulation 1, the scope of the market liberalization was restricted to the industrial and commercial users (except for agriculture and public utilities); we refer to this setting as the limited competition model. In China, the electricity price for households is not based on the underlying cost level and, thus, involves serious cross-subsidization. In order to maintain a stable level of electricity price for households, we assumed the electricity prices of households, agriculture and public utilities are kept at the pre-reform level which is different from the earlier literature. During such deregulation of the market, the cross-subsidization and the special funds must be maintained for adjusting the transmission electricity price, i.e., partial regulation remains in effect. In Simulation 2 , we assumed the liberalisation is fully accomplished by eliminating regulation and introducing deregulation to all users, including intermediate users and end users (i.e., households); we refer to this setting as the complete competition model. Although Simulation 2 is inconsistent with the current reform framework, the simulation results can be used as a reference for further considerations.

For the power sector, there are the following conventions:

(1) In the production module, there is no substitutability among the three sub-sectors of power generation, transmission and distribution. The total output of the power sector is the total output of the power generation sector.

(2) In the trade module, the import and export of the electric power takes place in the power distribution sector, and the residents will purchase electricity from the power distribution sector. The trade function of the electricity sector is governed by Equations (18)-(25).

(3) The production price of electricity in the distribution sector $\left(P A_{\text {elec- } d}\right)$ is determined by the commodity prices of the generation (PAelec-g) and transmission sectors (PAelec- $t$ ):

$$
P Q_{\text {elec }-g}+P Q_{\text {elec }-t}=P A_{\text {elec }-d}
$$

According to different reform scenarios, this paper simulated the deregulation of power generation and distribution, analyses the effects of electric power market reform on the economic efficiency of power enterprises and discusses the changes of input and output on the user side caused by the price fluctuations. In this model, the return on investment in the generation and distribution sectors was 
assumed to be zero as an exogenous shock, and the return on investment in the transmission sector was maintained at the base level.

For the power transmission sector, the following relationship holds:

$$
P Q_{\text {elec }-t}^{\prime}=(1+\text { markup }) P Q_{\text {elec }-t}
$$

where markup represents the level of sectoral returns with the base period return of the transmission sector being $10 \%$.

The introduction of competition in the power generation and distribution sectors has exerted shocks on the market equilibrium. According to the general equilibrium theory, the whole economy will approach another market equilibrium which will have an impact on the factor prices (including energy prices) and households' welfare. GAMS software was used to solve the CGE problem. The macroeconomic and microeconomic changes under two simulated situations are shown in Tables 15-17. The detailed discussion proceeds in the following sub-sections.

\subsection{Macroeconomic Effect Analysis}

According to the general equilibrium theory, the model redistributes the existing resources to various sectors of the market economy to meet supply and demand through inter-sectoral transactions. To put it otherwise, economic entities maintain the market balance through re-allocation of resources. Therefore, the inefficiency of the power sector ( $X$-inefficient behaviour) can be effectively eliminated through competition. As labour can move among the sectors, the deepening of electricity market reform might increase the labour income of residents by $0.024 \%$ and $0.018 \%$ (see Table 15 , line 8 ) for limited and full competition scenarios respectively. In addition to the increase in labour income, capital gains would also increase which indicates increase in residents' income by $0.037 \%$ and $0.031 \%$ (see Table 15, line 5) depending on the degree of market liberalisation. The increase in income affects the demand of residents which is reflected by the increase in consumption.

Table 15. Macro-level results of simulations (per cent changes from the baseline scenario).

\begin{tabular}{lccc}
\hline & Variable & \multicolumn{2}{c}{ Changes from Baseline Scenario (\%) } \\
\cline { 3 - 4 } & & Limited Competition & Full Competition \\
\hline 1 & Energy prices for households & -10.358 & -3.071 \\
2 & Energy composite use by households & 2.283 & 0.743 \\
3 & GDP & 0.612 & 0.441 \\
4 & $E V$ (billion yuan) & 7.710 & 2.316 \\
5 & Household income & 0.037 & 0.031 \\
6 & Enterprise income & 0.173 & 0.108 \\
7 & Government income & 0.065 & 0.044 \\
8 & Labor price & 0.024 & 0.018 \\
\hline
\end{tabular}

Note: EV is the abbreviation of Hicksian equivalent variation.

GDP growth of $0.612 \%$ and $0.441 \%$ (see Table 15 , line 3) indicates the positive impact of electricity price decline with regards to consumption by industry, government and households in both scenarios. According to the principle of the market equilibrium, the following reasons behind the GDP growth can be identified. First, considering the supply side, the drop in electricity price induces the substitution of electricity for other energy sources, which leads to the redistribution of resources through inter-sectoral transactions and more efficient use of factor inputs (labour, capital, energy and non-energy intermediate inputs). On the demand side, the increase of residents' income which is caused by the increase of real wages and the real capital gains results in an increasing aggregate demand (Akkemik, Oguz, 2011). According to the balance condition, the increasing aggregate demand induces expansion of the total output, which is quantified by GDP. 
Under different market liberalisation settings, social welfare increases by 7.710 billion RMB and 2.316 billion RMB (see Table 15, line 4). Note that the distribution of income between capital and labour remains unchanged in the hypothesis of the factor market. Because of the positive impact of deregulation on the factor prices, the revenue of government and enterprises has increased (see Table 15, line 6, line 7).

Comparing the outcomes of the two scenarios (i.e. different columns in Table 15), suggests that the social welfare under the limited competition would be higher than that under complete competition. In addition, due to the serious cross-subsidies of electricity prices for residents, agriculture and public utilities, the abolition of their protection will lead to the rise of electricity prices in the related industries. Accordingly, the price of energy-consuming composite products in the complete competition model is $7.287 \%$ (see Table 15, line 1) higher than that in the limited competition model. Thus, the quantity of consumer energy composite products is $1.54 \%$ (see Table 15, line 2) lower if compared to the limited competition model.

In summary, the price of residential consumer energy products would decline under the two simulation scenarios, while the consumption of energy products and GDP would go up to different extents. Thus, the new power market policy can bring positive effects and meet the objectives of the reform.

\subsection{Macroeconomic Effect Analysis}

\subsubsection{Input-Output Analysis}

In the first columns of Tables 16 and 17, we show the changes in sectoral total output under the limited competition model and complete competition model. One can note the output of the power sector could improve at different extents $(1.84 \%$ and $2.72 \%$, see Tables 16 and 17 , line 5, column 1) depending on the scenario. Because the incentive effect of complete competition model on electric power enterprises is greater than that of limited competition model, the output is $0.88 \%$ higher than that under the limited competition. However, the increase in the output of the power sector has a negative impact on the total output of other energy sectors (such as coal, oil and gas). Under the limited competition, the outputs of coal and oil and gas sectors decrease by $2.04 \%$ and $1.29 \%$ (see Table 16, line 2, 3, column 1) respectively, whereas under the complete competition mode the outputs decrease by $0.73 \%$ and $0.08 \%$ (see Table 17 , line 2,3 , column 1 ) respectively. This shows that the new policy is to change the structure of the energy-mix and increase the possibility of substituting electricity for other energy sources which is in line with the 13th Five-Year Plan as well as the core idea of energy revolution. Besides the power sector, the increase in total output is mainly concentrated in energy intensive industries such as mining and manufacturing which rely on electricity as a major input.

Table 16. Micro-level results of simulation for limited competition model (per cent changes from the baseline scenario).

\begin{tabular}{|c|c|c|c|c|c|c|c|c|}
\hline & Output & $\begin{array}{c}\text { Domestic } \\
\text { Consumption }\end{array}$ & $\begin{array}{c}\text { Intermediate } \\
\text { Input }\end{array}$ & $\begin{array}{l}\text { Commodity } \\
\text { Price }\end{array}$ & $\begin{array}{l}\text { Capital } \\
\text { Price }\end{array}$ & $\begin{array}{l}\text { Labor } \\
\text { Use }\end{array}$ & PEC & $Q E C$ \\
\hline$a g r$ & 0.43 & 0.25 & -0.27 & -0.33 & 0.91 & 0.64 & -1.18 & 1.13 \\
\hline$O G$ & -1.29 & -0.51 & -2.21 & -1.09 & -2.73 & -2.41 & - & - \\
\hline mining & 1.99 & 0.15 & 0.44 & -1.71 & 0.42 & 5.01 & -0.54 & 0.55 \\
\hline elec-D & 1.84 & 1.96 & 1.84 & -9.61 & - & -5.59 & - & - \\
\hline man & 1.32 & 0.46 & 0.83 & -1.34 & 0.51 & 6.11 & -0.24 & 0.73 \\
\hline cons & 0.22 & 0.93 & 0.65 & -0.87 & 0.03 & -7.72 & -0.35 & 0.24 \\
\hline serv & 0.41 & -0.11 & 0.34 & 0.09 & 0.84 & 0.51 & 0.02 & 0.87 \\
\hline$p u b$ & 0.54 & 0.18 & -0.23 & -0.08 & 0.37 & 0.39 & -0.13 & 1.32 \\
\hline
\end{tabular}


Table 17. Micro-level results of simulation for full liberalisation (per cent changes from the baseline scenario).

\begin{tabular}{ccccccccc}
\hline & Output & $\begin{array}{c}\text { Domestic } \\
\text { Consumption }\end{array}$ & $\begin{array}{c}\text { Intermediate } \\
\text { Input }\end{array}$ & $\begin{array}{c}\text { Commodity } \\
\text { Price }\end{array}$ & $\begin{array}{c}\text { Capital } \\
\text { Price }\end{array}$ & $\begin{array}{c}\text { Labor } \\
\text { Use }\end{array}$ & PEC & QEC \\
\hline agr & -0.26 & -0.19 & 0.07 & 0.17 & 0.57 & 0.47 & 0.18 & -0.72 \\
coal & -0.73 & -0.28 & -2.04 & -2.04 & -0.78 & -2.38 & - & - \\
OG & -0.08 & -0.37 & -0.02 & 0.02 & -2.48 & -2.71 & - & - \\
mining & 1.36 & 0.76 & -1.58 & -1.58 & 0.4 & 4.26 & -0.47 & 0.62 \\
elec-G & 2.72 & - & -1.92 & -6.27 & -10.09 & 0.52 & - & - \\
elec-T & 2.72 & - & 2.72 & 0.14 & - & -7.06 & - & - \\
elec-D & 2.72 & 0.78 & 2.72 & -8.15 & - & -4.92 & - & - \\
man & 0.89 & 1.72 & 0.33 & -1.27 & 0.36 & 3.78 & -0.24 & 0.65 \\
cons & 0.11 & 0.46 & 0.06 & -0.52 & 0.01 & -4.66 & -0.27 & 0.27 \\
serv & 0.21 & 0.96 & 0.11 & 0.06 & 0.73 & 0.32 & 0.02 & 0.63 \\
pub & -0.32 & -1.57 & 0.12 & 0.02 & 0.15 & 0.19 & 0.07 & -0.38 \\
\hline
\end{tabular}

However, the output of agriculture and public utilities showed different trends under the two scenarios. Under the limited competition scenario, the outputs of both sectors increase, while under the complete competition model the outputs of both sectors go down to a substantial extent. This is mainly due to the fact that in the first scenario, the electricity prices for agriculture and utilities remain at the same level, which is much lower than the level of electricity price under the complete competition. The increase in electricity price leads to a decrease in the outputs of the two sectors.

The efficiency of the generation sector can be measured by considering the reduction in the intermediate input. From Tables 16 and 17, one can observe that the efficiency growth rate of the generation sector is about $1.08 \%$ and $1.15 \%$. According to the equilibrium theory, the improvement in efficiency is due to the withdrawal of inefficient employees and the entry of new more efficient companies. The increase in output will inevitably lead to the increase of the intermediate input of the transmission and distribution sectors, which is $1.84 \%$ and $2.72 \%$, respectively, under the limited competition model and the complete competition model. It is assumed that there is no energy substitution in the energy production sector. Thus, the decrease in the output of the fossil energy sector (coal, oil and gas), renders a proportional decrease in the intermediate input. For agriculture and public utilities, electricity prices and sector outputs are quite different under the two simulation scenarios, which also leads to higher differences in the intermediate inputs. Under the limited competition model, due to the electricity price protection policy, the electricity price is lower than the market price. This renders lower value of the intermediate input and higher output. However, in the compete competition model, the protection of electricity price vanishes and the intermediate input increases with the output decreasing.

\subsubsection{Commodity Prices and Consumption}

The liberalisation of the power distribution sector brings about changes in the price system of the market economy. The CGE model can approximate the resulting output commodity prices for each sector under the market equilibrium conditions based on the price equilibrium mechanism. Under the limited competition model, the supply price of the power generation sector drops by $6.80 \%$ (see Table 16, line 5, column 4), and the supply price of the electricity sales sector decreases by $9.61 \%$ (see Table 16, line 7, column 4 ). The reason behind the decline in the price of electricity supply is the increase in production efficiency of the sub-sectors. As the non-energy sectors takes the cheaper electricity as an intermediate input, the change of electricity price will inevitably lead to the price changes of non-energy products. Given the transmission sub-sector remains under government supervision, the price of the transmitted electricity does not change. Besides agriculture and public utilities, the composite energy price changes basically follow the same pattern across the sectors when comparing the cases of limited and complete competition. Overall, the impact of the liberalisation is 
positive for each sector. Note that the phasing out of electricity price regulation induces the growth in the price of the composite energy input in the agricultural and utility sectors.

In addition, commodity prices and domestic consumption showed an inverse relationship. Specifically, for the non-energy sectors, commodity consumption increases with price reduction under the limited competition model. In the power generation sector, non-electric energy sectors decrease their output due switching to electricity (which becomes cheaper) if opposed to fossil fuels being used as final energy. Under the completely competitive scenario, domestic consumption of coal, oil and gas sector outputs decreases to a lower extent than it is the case in partial liberalisation as output of the generation sector goes up. For agriculture and public services, domestic consumption of their outputs decreases due to higher prices, and the consumption of public services decreases to the greatest extent. For other sectors, the change is basically the same as that under the limited competition mode.

\subsubsection{Factor Market Analysis}

Capital is not allowed to move across the sectors which implies the rate of return on investments vary across the sectors. The results show that the rate of return on investment changes in each sector due to liberalisation of the electricity market and the direction of change is the same under the two scenarios. The return on investments declines in the electricity sector as electricity prices are no longer maintained at the higher level. Among the sub-sectors, the power generation sub-sector faces the most serious change, $8.22 \%$ and $10.09 \%$ increase in the ROI depending on the scenario assumed. These results indicate that deregulation reduces the profit margins of the power generation industry (see Tables 16 and 17, column 5).

Regarding labour demand (Tables 16 and 17, column 6), there are five sectors where labour demand decreases due to electricity market deregulation with the transmission sub-sector facing the most serious decline. Since this paper assumes labour mobility across the sectors, the reduced labour demand in some sectors is compensated by increasing demand in the other ones proportional to the changes in their outputs (most of the freed-up labour force is transferred to energy-intensive industries). In relative terms, the change in demand for labour force is very small if compared to the total amount of the labour force. This shows that the deregulation does not simply decrease employment in the deregulated sector, but rather triggers increase in labour demand across the other sectors and thus ensures redistribution of labour force by the market mechanisms (the invisible hand).

\subsubsection{Energy Composite Commodity Analysis}

Under the limited competition model, the prices of power, coal, oil and gas all decline. The changes in energy product price will inevitably lead to the price changes of energy composite commodities. In addition, the price of energy composite products decreases in non-energy sectors, except for the service sector.

Due to the inverse relationship between price and demand, the decline in energy input prices inevitably leads to an increase in consumption of energy composite commodities of $4.84 \%$ (see Table 16 , column 8 ) in the limited competition case. Due to the abolition of electricity price protection, the price of energy composite commodity increases in agriculture and public utilities under the complete competition scenario. In addition, the prices of energy composite products decrease in most of the other sectors, which induces an increase in the demand for energy composite commodities. Thus, deregulation is likely to stimulate the demand of the energy input.

\section{Conclusions}

In this paper, we applied a CGE model for the assessment of the impacts of reform of China's electricity industry. The results indicate that the reform can effectively reduce both the electricity price and composite energy price. A complete competition in the electricity sector of China would lead to an increase in electricity prices for households due to the abolishment of serious electricity cross- 
subsidies. The results imply reallocation of labour force across the sectors following the phase-out of the regulations. Therefore, professional training and other services should be maintained in order to ensure a smooth transition. From the perspective of sustainability, the liberalisation of the electricity market is likely to fuel the substitution of electricity for other energy sources. Thus, improving the sustainability of electricity generation (by removing backward capacity and switching to renewables) may improve the sustainability of the whole economy of China.

The present research is limited in that the CGE model was built on a rather limited dataset. Therefore, further research should address the following points. First, the CGE model constructed in this paper is a static model, which uses single-year data as the baseline data. Indeed, one can establish a dynamic CGE model to study the effects of the reform on the economy. Second, the substitution parameters used in this model are based on earlier literature. One could further calibrate the parameters involved so that they would represent China's economic characteristics in a more accurate manner.

Author Contributions: Data curation, J.Y. and K.L.; Investigation, J.Y. and K.L.; Supervision, Q.Y.; Writing-Original Draft, J.Y.; Writing-Review \& Editing, T.B. and D.S.

Funding: This work was funded by the Youth Fund Project of Beijing Wuzi University (No. 2019XJQN04), Research Base Project of Beijing Social Science Foundation (No. 16JDGLB023) and 2018 Key Projects of Philosophy and Social Sciences Research, Ministry of Education, China (No. 18JZD032).

Conflicts of Interest: The authors declare no conflict of interest.

\section{References}

1. Song, M.; Wang, S. Market competition, green technology progress and comparative advantages in China. Manag. Decis. 2018, 56, 188-203. [CrossRef]

2. Song, M.; Peng, J.; Wang, J.; Dong, L. Better resource management: An improved resource and environmental efficiency evaluation approach that considers undesirable outputs. Resour. Conserv. Recycl. 2018, 128, 197-205. [CrossRef]

3. Chen, J.D.; Cheng, S.L.; Nikic, V.; Song, M.L. Quo vadis? Major players in global coal consumption and emissions reduction. Transform. Bus. Econ. 2018, 17, 112-132.

4. Chaudhary, R.; Bisai, S. Factors influencing green purchase behavior of millennials in India. Manag. Environ. Qual. 2018, 29, 798-812. [CrossRef]

5. Soava, G.; Mehedintu, A.; Sterpu, M.; Raduteanu, M. Impact of renewable energy consumption on economic growth: Evidence from European Union countries. Technol. Econ. Dev. Econ. 2018, 24, 914-932. [CrossRef]

6. Wang, X.L.; Wu, L.H. Determinants of workers' attitude toward low-carbon technology adoption: Empirical evidence from Chinese firms. Chin. J. Popul. Resour. Environ. 2017, 15, 80-86. [CrossRef]

7. Xu, Y.C. Sinews of Power: The Politics of the State Grid Corporation of China; Oxford University Press: Oxford, UK, 2016.

8. Wang, Q.; Chen, X. China's electricity market-oriented reform: From an absolute to a relative monopoly. Energy Policy 2012, 51, 143-148. [CrossRef]

9. Fan, M.T.; Zheng, Y.X. General equilibrium analysis of the impact of trade liberalization on China's economy. J. World Econ. 2000, 4, 16-26. (In Chinese)

10. Koesler, S.T. Computable general equilibrium modelling in the context of trade and environmental policy. Chembiochem 2015, 7, 158-164.

11. Yahoo, M.; Othman, J. Employing a CGE model in analysing the environmental and economy-wide impacts of CO2 emission abatement policies in Malaysia. Sci. Total Environ. 2017, 584, 234-243. [CrossRef]

12. Wei, W. An analysis of China's energy and environmental policies based on CGE model. Stat. Res. 2009, 26, 3-12. (In Chinese)

13. Li, S.T.; Hou, Z.Y.; Zhai, F. Medium and long term: China's economy still has the potential for rapid growth. China Ind. Econ. 2000, 6, 15-19. (In Chinese)

14. Shi, J.R.; Ling, T.; Le-An, Y.U.; Bao, Q. Impacts of coal resource tax reform on China's economy based on a CGE model. Syst. Eng. Theory Pract. 2015, 35, 1698-1707. 
15. Scaramucci, J.A.; Perin, C.; Pulino, P.; Bardoni, O.F.G.J.; da Cunha, M.P.; Cortez, L.A.B. Energy from sugarcane bagasse under electricity rationing in Brazil: A computable general equilibrium model. Energy Policy 2006, 34, 986-992. [CrossRef]

16. Hosoe, N. The deregulation of Japan's electricity industry. Jpn. World Econ. 2006, 18, 230-246. [CrossRef]

17. Akkemik, K.A.; Oguz, F. Regulation, efficiency and equilibrium: A general equilibrium analysis of liberalization in the Turkish electricity market. Energy 2011, 36, 3282-3292. [CrossRef]

18. Rodrigues, R.; Linares, P. Electricity load level detail in computational general equilibrium-Part I-Data and calibration. Energy Econ. 2014, 46, 258-266. [CrossRef]

19. Rodrigues, R.; Linares, P. Electricity load level detail in computational general equilibrium-Part II-welfare impacts of a demand response program. Energy Econ. 2014, 47, 52-67. [CrossRef]

20. Hwang, W.S.; Lee, J.D. A CGE analysis for quantitative evaluation of electricity market changes. Energy Policy 2015, 83, 69-81. [CrossRef]

21. Farajzadeh, Z.; Bakhshoodeh, M. Economic and environmental analyses of Iranian energy subsidy reform using Computable General Equilibrium (CGE) model. Energy Sustain. Dev. 2015, 27, 147-154. [CrossRef]

22. Capros, P.; Paroussos, L.; Charalampidis, I.; Fragkiadkis, K.; Karkatsoulis, P.; Tsani, S. Assessment of the macroeconomic and sectoral effects of higher electricity and gas prices in the EU: A general equilibrium modeling approach. Energy Strategy Rev. 2016, 9, 18-27. [CrossRef]

23. Bataille, C.; Melton, N. Energy efficiency and economic growth: A retrospective CGE analysis for Canada from 2002 to 2012. Energy Econ. 2017, 24, 118-130. [CrossRef]

24. Melnikov, N.B.; O’Neill, B.C.; Dalton, M.G.; van Ruijven, B.J. Downscaling heterogeneous household outcomes in dynamic CGE models for energy-economic analysis. Energy Econ. 2017, 65, 87-97. [CrossRef]

25. Mu, Y.Q.; Wang, C.; Cai, W.J. Using sectoral approach as complement to the INDC framework: An analysis based on the CGE model. Energy Procedia 2017, 105, 3433-3439. [CrossRef]

26. Liu, Y.; Hu, X.; Feng, K. Economic and environmental implications of raising China's emission standard for thermal power plants: An environmentally extended CGE analysis. Resour. Conserv. Recycl. 2016, 121, 64-72. [CrossRef]

27. Li, W.; Jia, Z.; Zhang, H. The impact of electric vehicles and CCS in the context of emission trading scheme in China: A CGE-based analysis. Energy 2017, 119, 800-816. [CrossRef]

28. Zhang, W.; Yang, J.; Zhang, Z.; Shackam, J.D. Natural gas price effects in China based on the CGE model. J. Clean. Prod. 2017, 147, 497-505. [CrossRef]

29. Zhang, S.; Wang, C.; Cai, W. How shale gas will shape China's future? An evaluation based on dynamic energy-CGE model. Energy Procedia 2017, 105, 3349-3354. [CrossRef]

30. Liu, Q.; Liu, Y.; Xu, J.T. Economic and environmental effects of improved auto fuel economy standard in china: A CGE analysis. Acta Sci. Nat. Univ. Pekin. 2016, 52, 515-527.

31. Ge, J.; Lei, Y. Policy options for non-grain bioethanol in China: Insights from an economy-energy-environment CGE model. Energy Policy 2017, 105, 502-511. [CrossRef]

32. Xiao, Y.; Wang, X.; Wang, X.; Wu, Z.; Liu, W. The Coordinated development path of renewable energy and national economy in China considering risks of electricity market and energy policy. IEEE Trans. Ind. Inform. 2017, 13, 2556-2575. [CrossRef]

33. Liu, Y.; Zhou, M. The impact of coal resource tax reform on the Chinese economy: A CGE analysis. Singap. Econ. Rev. 2018, 63, 555-565. [CrossRef]

34. Yang, H.W.; Cui, C. Application of CGE model to analyze environmental and social benefits of gas generation in China's power sector. Energy Environ. 2006, 1, 10-14. (In Chinese)

35. Zhang, Y.G. Potential Effects of electricity price change on industrial structure-empirical analysis from different angles. J. N. China Electr. Power Univ. 2006, 10, 36-41. (In Chinese)

36. Tan, X.D.; Zhao-Guang, H.U.; Meng, L.I. Electric policy simulation based on computable general equilibrium model. Power Syst. Technol. 2007, 31, 55-60. (In Chinese)

37. He, Y.X.; Zhang, S.L.; Yang, L.Y.; Wang, Y.J.; Wang, J. Economic analysis of coal price-electricity price adjustment in China based on the CGE model. Energy Policy 2010, 38, 6629-6637. [CrossRef]

38. Song, M.L.; Cui, L.B. Economic evaluation of Chinese electricity price marketization based on dynamic computational general equilibrium model. Comput. Ind. Eng. 2016, 101, 614-628. [CrossRef] 
39. He, J.H.; Shen, K.T.; Xu, S.L. A CGE model of carbon tax and carbon dioxide emission reduction. J. Quant. Tech. Econ. 2002, 10, 39-47. (In Chinese)

40. Ma, S.G. Effects of sulfur tax on Chinese sulfur dioxide emission and energy consumption. China Ind. Econ. 2008, 22, 20-30. (In Chinese) 